\title{
Using a Judgemental Analysis System to Evaluate the International Mainframe and Computer Market
}

DOI:

10.1007/978-3-319-50008-9_169

\section{Document Version}

Accepted author manuscript

Link to publication record in Manchester Research Explorer

\section{Citation for published version (APA):}

Holland, C. P., Naude, P., \& Heptonstall, B. (2017). Using a Judgemental Analysis System to Evaluate the International Mainframe and Computer Market. In The Customer is NOT Always Right? Marketing Orientationsin a Dynamic Business World: Proceedings of the 2011 World Marketing Congress (Developments in Marketing Science: Proceedings of the Academy of Marketing Science). Springer Nature. https://doi.org/10.1007/978-3-31950008-9_169

\section{Published in:}

The Customer is NOT Always Right? Marketing Orientationsin a Dynamic Business World

\section{Citing this paper}

Please note that where the full-text provided on Manchester Research Explorer is the Author Accepted Manuscript or Proof version this may differ from the final Published version. If citing, it is advised that you check and use the publisher's definitive version.

\section{General rights}

Copyright and moral rights for the publications made accessible in the Research Explorer are retained by the authors and/or other copyright owners and it is a condition of accessing publications that users recognise and abide by the legal requirements associated with these rights.

\section{Takedown policy}

If you believe that this document breaches copyright please refer to the University of Manchester's Takedown Procedures [http://man.ac.uk/04Y6Bo] or contact uml.scholarlycommunications@manchester.ac.uk providing relevant details, so we can investigate your claim.

\section{OPEN ACCESS}




\title{
USING A JUDGEMENTAL ANALYSIS SYSTEM TO EVALUATE THE INTERNATIONAL MAINFRAME AND COMPUTER MARKET
}

\author{
Christopher P. Holland, University of Manchester, U.K. \\ Peter Naude, University of Manchester, U.K. \\ Barrie Heptonstall, IBM Systems and Technology Group, U.K.
}

\begin{abstract}
A judgemental analysis system that supports and facilitates the use of multi-criteria evaluation was used to evaluate the mainframe computer market. The work was conducted with a large systems vendor. The purpose of the research was to compare the relative perceptions of customers and the internal sales force for different computer platforms: mainframe, midrange, Windows NT and Unix servers. The product attributes were defined by working with the mainframe supplier and each of the platforms was evaluated against each attribute. Data were collected from interviews with senior managers from fifteen customer organizations in a range of industries including banking, manufacturing, insurance and distribution. Data were also collected from six members of the European sales team to enable a dyadic comparison between customer evaluations and supplier perceptions of the same market. The key results are that significant differences exist between the relative importance of individual attributes between the customers and members of the supplier's sales team, and clear patterns emerge on the scoring of each platform against the attributes. The implications for using a multi-criteria tool for data collection and analysis are outlined, and the importance of the research results for managers and academics involved in the IT industry are described.
\end{abstract}

\section{INTRODUCTION}

The purpose of this study is to demonstrate how a multi-criteria decision making tool can be applied to market analysis in a business-to-business environment. A specialized piece of software, the Judgemental Analysis System (JAS), has been developed to make the data collection and analysis process practical from the perspective of both the market researcher and the subject of the study. Based on earlier projects in other markets (e.g. see Lockett and Naude 1991, Naude and Lockett 1993) the approach has face validity for managers who adapt to use the tool quickly and effectively to structure their analysis and evaluation of competing purchasing options in their supplier consideration-set. In this paper, the approach is extended to include the perceptions of both the buyers and the sellers in the European mainframe computer market, where mainframe computers compete against other platform architectures including the AS/400, Windows NT servers and Unix systems.

Mainframe computer systems are traditionally sold to government bodies and large corporations. These include major financial institutions, utilities companies, airlines, and manufacturing companies. IBM has been a global market leader in the mainframe market since its inception and competitors, particularly Japanese companies, have strived to attack IBM's market share. See Anchordoguy $(1988,1989)$ for a detailed analysis of how the Japanese computer industry built up its technology and market power throughout the 1960s to the early 1980s through a combination of collaboration in areas such as R\&D, aided by the proactive involvement of the Ministry of International Trade and Industry (MITI) and then through international alliances with US and European computer firms.

Typical transactions are of the order of $\$ 0.5$ million to $\$ 10$ million, although larger transactions are not uncommon. Gross margins for these systems may be of the order of $70 \%$. A large proportion of these mainframe sales have been the replacement market. However new technology means customers are increasingly able to upgrade their systems, rather than having to face the costs of wholesale replacement. This means that a large source of revenues for companies such as IBM, Hitachi Data Systems (HDS) and Amdahl is fast disappearing. In addition, there is increased competition from smaller networked systems, e.g. mid-range machines such as the AS/400 and servers that use Unix or Windows. As networked systems become more powerful these smaller systems become more attractive because of their flexibility and lower hardware costs.

The traditional mainframe suppliers are facing a $20 \%$ to $30 \%$ annual price decline, and need to increase the usage of equipment in order to maintain (or even increase) revenues. The large vendors vigorously contest each new mainframe purchasing decision. At the same time, the mainframe companies must compete against networked server or even PC-based solutions. In an historical analysis of the computer industry Malerba et al (1999) identified three main computer architectures: mainframe computers; minicomputers and networked Personal Computers (PCs). Christensen (1997) also uses the same categorization scheme of computing architectures to illustrate the disruptive impact of minicomputers on the mainframe market and then personal computers on the minicomputer market. 
It must be remembered that from the perspective of a customer wishing to buy a new computer architecture for a large-scale application of whatever type, or to replace an ageing mainframe, all three architectures are likely to be in their consideration set, i.e. mainframe, some type of mid-sized machine such as the AS/400 and then networked PCs/Servers running either Windows NT or Unix. The mainframe category still exists and the equivalent to the minicomputer in this study is the AS/400. The networked server category is divided into two sub-categories defined by the operating systems of Windows NT and Unix. We have therefore adapted the broad historical classification to define four competing architectures. Working with one of the large mainframe suppliers, the objective of this paper is to explore the use of a judgemental modelling system to develop our understanding of how buyers perceive the overlap between the capabilities of high-end and low-end machines, and also to explore how the company should compete in the markets for new age applications, e.g. Business Intelligence/Data Mining (Watson and Wixom 2007), ERP (Holland and Light 1999), e-Business (McEachern and O’Keefe 1998), Server Consolidation (Waldspurger 2002) as well as the more traditional industry applications.

\section{Defining The Market}

The replacement mainframe system market typically has two groups of customers. The first group consists of relatively small organizations that purchased machines in the 1970 s to early 1980 s. They tend to run much older systems and are not really large enough to justify the costs of newer centralized solutions, but which continue to do so for historical reasons. The second group consists of large organizations in the public and private sectors. They tend to run old applications on large machines and either could or already are adding new applications to their installation. For this second group of customers, changes in their business and IT strategies generates new opportunities because of the need for more powerful machines or newer machines that are more efficient and have lower running costs.

It is the second group that we focus on here, since any systems implementation is likely to be of a large scale with a corresponding large requirement for capacity. There are very few new potential customers for these machines, primarily due to the fact that the initial costs of purchasing and operating a system are high, and the system does not become very cost effective until it is supporting several thousand users. While most large organizations already have systems, newer companies tend to grow up with alternative platforms.

One potential way of segmenting the market would be to look at industry sectors, and look for commonalties. The industry has traditionally operated this way, with focus on segments such as Banking, Finance and Securities; Insurance; Distribution; Government, etc. Increasingly, however, suppliers are seeking to understand their markets by product and solution areas, with sales teams working in each of these across industry sectors. Whilst this would appear to be a logical approach, there are two important aspects to appreciate. First, customers may not relate to these categories. For example they would think of a system to generate mail-shots as a "marketing system", rather than "business intelligence". Second, many of the solution areas are converging, for example most Enterprise Resource Planning (ERP) systems have data warehouses built into them, and have web-enabled the system for e-commerce. In spite of these potential shortcomings, the following are some of the solution areas typically found in the higher end systems: Business Intelligence/Data Mining; Enterprise Resources Planning; Server Consolidation; and E-Commerce and E-Collaboration. It is clear that mainframe computer sales are a highly specialized market that falls within the broader area of high-technology marketing as described by Mohr et al (2010).

It is worth making a brief comment about the Decision Making Unit (DMU) involved in a buying decision. Being either a complex modified re-buy or else a new task (Robinson et al, 1967), the DMU is usually complex (Crissey 1998). Members often involved include Board Member; Senior User Manager; Application Development; IT Manager/Director (CIO); User Groups, IT Operations Manager; Consultants; and independent software vendors.

The different industrial segments and solution groups identified above suggested to us a matrix approach was required in our sampling, onto which had to be overlaid considerations surrounding the DMU. This led us to develop a matrix defined by two axes: industry segment (e.g. financial services, manufacturing, retailing); and application area (e.g. business intelligence, enterprise computing, e-business). This model has been used to position individual customers. Of course, there may also be customers who sit across a number of these boxes - for example one customer decision maker may purchase both ERP systems and an e-business application.

There are five potential results for market requirements and which could come from a full-scale market analysis of this type:

1. These are consistent across all industries and all solution areas.

2. These are consistent across all industries but vary by solution area.

3. These vary across industries but are consistent across all solution areas. 
4. These vary across industries and solution areas.

5. These vary for each and every customer - i.e. the market is always a unique market of one.

For the purposes of this study, and given that very little market research data of this type actually exists within the industry at present, it was decided that the objective was to spread the study across as mixed a population as possible in order to get the broadest view possible and to begin to develop some theories about the market.

There was a requirement to identify differences in customers' needs and perceptions across each of the sectors in order to form and articulate a clearer and differentiated marketing message. Historically, the vendor had not considered server and mid-range computer systems to be in the same competitive-set as a mainframe. Information on how customers perceived mainframe solutions versus other technology platforms had therefore not been considered and there was no market intelligence available within the company.

\section{RESEARCH METHOD}

There are two fundamental approaches for carrying out a more scientific evaluation of customer requirements and how System/390 scores against these. From Naude and Lockett (1993), the Cost-Ratio Method (under which a financial value is related to all positive and negative aspects of a proposition in order to attempt to develop an overall financial rating for each option) and Multi-Criteria methods. In the latter, all relevant attributes are identified, these are prioritised, and the options are rated against these. This creates an overall rating for each option. The second of these, Multi-Criteria Decision Making was used for this exercise as it is a methodology which will completely and accurately reflect customer priorities and perceptions.

In order to position the analytical research method in a competitive context, a model of the use of judgemental analysis to evaluate markets is shown in figure 1. Market evaluation takes place in a competitive context. A firm's existing sales and marketing strategy is taken as the starting point in order to define the relevant set of competitors and product attributes. The current approach to the market is also captured. The market evaluation is an analysis of the different viewpoints of managers in the customer organization and managers in the supplier organization, in this case, sales staff. There is also a synthesis of the different perspectives. The initial results are the salience of product attributes and competitor scores, which together give a picture of the overall market.The interpretation of the results informs the evolution of the future sales and marketing strategy of the supplier.

Data were collected in personal interviews with senior purchasers of information technology equipment in the UK and Holland. The interviews were facilitated by the use of a PC-based judgemental modelling package JAS (see Islei and Lockett 1988; Naude et al 2000) that helps decision makers evaluate different options using a compensatory approach based on pairwise comparisons of a set of attributes and alternatives. Comparative studies of the relative importance of different attributes and the performance of competitors on each attribute frequently lack substantive measures of the extent to which factors differ from each other. In tackling this problem, judgemental modelling is similar in concept to other multi-criteria decision making (MCDM) approaches such as the AHP (Saaty 1980, Wind and Saaty 1980). Both are based on an underlying compensatory model (Wind 1982), which decomposes a problem into three separate hierarchical issues:

1. What attributes are important to users in making purchasing decisions?

2. How do attributes vary in importance?

3. How do individual suppliers perform relative to one another?

By using this multi-criteria approach facilitated by JAS, it was possible to understand both the relative importance of a range of product attributes by weighting them, and also to score the current perceptions of the main server platforms in the market today (UNIX, NT, AS/400, S/390) on these different attributes. The focus of the paper is on the analysis of the business to business marketing data outlined in figure 1 to inform future sales and marketing strategy development. But the research could equally be viewed as a case study and used to generalize the findings to theory development as per Eisenhardt (1989). The case study aspect of the research is being developed as part of another research programme.

\section{Research Questions}

The research aimed to answer three main questions:

1. What are the key attributes of customers' requirements at the time of purchase that lead them to select one server technology platform over another? 
2. What is the current perception in the market of the four main server platforms scored against these key attributes?

3. What insights can be gained from this type of research to inform the sales and marketing strategy for IBM? Related to the specific insights, can the findings be generalized into theories that can be tested in future research and applied in other high-technology marketing environments?

This research was not aimed at addressing the choice of supplier but rather the choice of architecture. In most customer buying processes, choice of architecture (e.g. UNIX versus S/390) is made before tendering for the supply of the hardware (e.g. following a UNIX choice, IBM, HP and Sun might all be asked to tender). The focus on different architecture in this study corresponds to how economic analyses of competition in the computer industry has revealed that competition takes place between computer 'platforms' rather than individual competitors (e.g. Bresnahan and Greenstein 1999). The term computer platform corresponds to the mainframe, minicomputer and networked PC architecture classification used in this paper.

There are, of course, situations where these decisions overlap - clearly an AS/400 decision, for example, will always be an IBM decision (although there will be a separate decision made as to which IBM Reseller will supply the machine). A decision for System/390 does not mean IBM will automatically win the business - HDS and Amdahl will almost always be invited to tender and are likely to take a proportion of this business. The important objective of this research will be to define a proposition that contributes towards identifying whether a mainframe approach is a credible option for new application workloads.

All customers were therefore asked to score the platforms as if their required application was supported on it. Four server platforms (Unix, Windows NT, AS/400, and System/390) were addressed. These have been selected because they are genuine options for customers when seeking platforms for new applications - thus System/390 does compete against AS/400, NT and UNIX in certain customer situations. Other proprietary platforms, for example Unisys mainframes, were left from the survey on the basis that they have relatively small market shares and are very rarely seen nowadays as a competitor to System/390.

Based on our experiences from earlier research in other industries, suppliers are usually able to specify correctly the list of attributes that customers require, but are usually unable to score these accurately compared with actual customer ratings. The list in Table 1 was developed within IBM on the basis of IBM internal reports and existing research (Hammon 1998, Harmer 1997, IBM 1988, 1999, Rafiq 1998 and Crissey 1998). Both IBM sales staff and customers scored the model.

In order to take a broad snapshot of the market, it was decided to spread the interviews across a broad range of industries, customer positions, installed systems, and solutions areas. A total of fifteen customer buyers (identified as Cus 1 to Cus 15) were interviewed using the WINJAS software tool to capture, store and analyse the data (Islei and Lockett, 1988). All fifteen customers had recently made a server purchase for one of the solutions areas. Most had gone through a selection exercise during that purchase, and therefore had a recent view of the relative strengths of the platforms. All were experienced executives in either the business application or computer management of IT systems. The spread of interviews across industry sectors and application areas is shown in table 2.

In addition, six sales representatives of the company with sales experience covering all four types of platforms were also interviewed. The core research questions were concerned with identifying and comparing the supplier perceptions of the buyers' needs compared with the buyers' actual views. There are two separate elements to the analysis, those concerning the relative importance of the product attributes ("Attribute Salience Analysis") and those that are concerned with the overall positioning of the four servers against these attributes ("Server Positioning Analysis").

\section{RESEARCH RESULTS}

\section{Product-Attribute Salience Analysis}

The customer scoring of the product attributes is shown in table 3. For each customer the sum of scores across the attributes sums to 100 . The scoring system represents the weighting that the customer places on each attribute relative to the other attributes.

From these, together with the customers' comments, it is possible to build the following theories about what the customers find important. There was quite a degree of variance between the customers with five of the six attributes being selected as the most important attribute by at least one customer. The widest range for a single attribute scored by different customers was 48.2 by Cus 5 , and 4.2 by Cus 8 when scoring the importance of hardware resilience. There were similar large variances 
for the other attributes. This does suggest that although this survey can be used to draw some overall market conclusions, there is also an important aspect in that the market can be a "market of one".

Hardware resilience was clearly the most important criteria overall, with seven customers selecting this as their most important attribute. Two customers, Cus 1 and $\mathrm{Cus} 8$, scored hardware resilience very low, explaining that although hardware resilience is extremely important, they now expect all servers to offer this and therefore they do not count it as an important attribute in a selection exercise. Setup Time was clearly the least important criteria. It failed to have even one customer select it as his most important criteria, and only one scored it as his second most important. This is actually quite surprising given the level and speed of competition in most markets. This, together with the pace of change in the IT industry itself, would suggest that setup time (or time to market for a new system) would be very important. A number of customers explained that they felt it was more important to have the right system and one which was able to offer a high level of service, than to have a poor performing system up and running quickly.

This fits, then, with the high levels of importance attached to application availability, which was ranked as the second most important criteria. Cus 3 explained that he is making a trade-off in favour of having a highly available system that takes longer to set up, as opposed to a less available system quickly. Several customers said that hardware resilience and application availability are absolutely key, and that all the other attributes are significantly less important. They said that IT systems are now so critical to their business that they cannot afford to compromise these. Cus 5 explained this by saying that "We do whatever it takes to get a world class infrastructure and we don't take any shortcuts".

Manageability scored relatively highly, in third place, although four customers rated it as their most important attribute (the 2nd highest number of "1" ratings). Cus 2, an IT Manager, rated this as his number one criteria, "If I can manage it, it will be cost effective and will mean that we can offer up time and resilience". Total Cost of Ownership was, perhaps surprisingly, put in fourth place with an average rating of just 15.2. This is surprising because most hardware manufacturers, including IBM and its High End Systems Business, promote this attribute of their offering most strongly. Again that three other attributes come above Cost of Ownership in priority reflects the high degree of importance which customers place on their systems. One customer (Cus 2) rated total cost of ownership as his second most important attribute by explaining that "Costs are always important as they have to go in the business case and without that we can't get a project approved". Cus 1 rated this low, but explained that whilst Cost of Ownership is low in importance, Return on Investment would be very high. It is, perhaps, surprising that more customers did not draw this distinction, although it is hard to picture what a Return on Investment case would look like for a server, without looking at a complete project. This could make an interesting topic for a further study.

Scalability, which, along with Cost of Ownership, is one of System/390's top two aspects of its proposition today also scored very low in importance. Most customers said that all platforms are able to offer sufficient scale now, so it is fairly academic as to the extent to which these go. Cus 1 rated it as his most important attribute. He explained that this was because his application, at a large bank, had to support many thousands of users and huge amounts of data, and many servers would not support this. There appears then, for this customer at least, to be an interesting compensation is his attribute scoring to take account of situations where servers are reaching their limits. Clearly an attribute would become most important where this is the case. Another customer, Cus 3, said that scalability includes the ability to have small, as well as large, implementations. This affected his scoring of the platforms, since his perception was that not all platforms could support small implementations. The results from the supplier attribute scoring process based on the individual salesperson's understanding of customer requirements is shown in table 4.

Interestingly, the internal results are significantly different in two ways to those of the customers. The first point to note is that whilst the customers scored hardware resilience as their most important attribute, the IBM salesmen thought that this was the least important criterion. The salesmen offered the explanation that customers were no longer concerned with hardware resilience. Perhaps this identifies a worry in our customers' minds that IBM thinks has been fully dealt with.

Secondly, IBM's top attribute was total cost of ownership, which came just fourth in the customer ranking. This is, perhaps, because the salesmen handle price negotiations as a key aspect of their job, and they have failed to distinguish between the common objective of customers to achieve a good price for their purchase, and how important this is in the overall scheme to the customer. Clearly this is a vitally important point to note because it offers a potential opportunity to preserve IBM's margins if the sales force can capitalize on the factors, which their customer really finds important. In other respects, the scores are very similar with both IBM employees and customers placing application availability and manageability in their top three, and scalability and setup time in the bottom three. A comparison of the supplier and customer scores is shown in table 5 . 


\section{Server Positioning Analysis}

The results of the fifteen customers scoring the platforms against the attributes are shown in table 6 . The method for calculating a customer's score for each platform is as follows. For each platform, a customer allocates 100 points across the competing platforms of Unix, NT, AS/400 and System/390 for each attribute (i.e. scalability, hardware resilience, application availability etc.). The scores for each attribute are then weighted according to the customer weighting of the attributes presented in table 3.

Given that equivalent numbers of customers had each platform installed (roughly 10 out of 15 for each platform) and most of the customers had examined all the platforms during a recent selection exercise, the results should reflect not only perceptions but also actual experience. System/390 was the clear leader, with a higher average score than the next two platforms - AS/400 and NT combined. This run-away result is actually quite surprising, given that it does not reflect IBM's wider experience in the market. Part of the reason for this may be that support of the application was removed from this study, and System/390 has been relatively very poor in this area until very recently. Even now, it still supports many fewer applications than the other three platforms. Further analysis in the following sections will explain this further.

The other potential reason for S/390's poorer performance in the market than in this study is that the IBM sales' perceptions of $\mathrm{AS} / 400$ are higher than $\mathrm{S} / 390$. It is very likely that the IBM sales-force is bidding AS/400 solutions to customers who would probably prefer a System/390 solution, and the customers are as a result buying either NT or UNIX. This is a very worrying potential conclusion that needs further analysis.

Ten of the fifteen customers ranked System/390 as the top platform, including Cus 5 who does not have a System/390 installed in his organization. His explanation was that he saw it as the only true enterprise platform for extremely large organizations meeting the broad spectrum of requirements that a large company would have. An AS/400, UNIX, and NT customer for many years - he said there were faults with them all and he was now considering a System/390 for his own company. AS/400 was rated some way behind System/390, but with a clear lead over NT and UNIX. Four of the fifteen customers however did score it as their top platform. Cus 7 scored the AS/400 server highest, but complained of high software upgrade charges once he purchased his systems. NT, perhaps the most popular platform for new application workloads, was rated only third - very close to UNIX which was placed a very surprising fourth. Given that most PC server and UNIX vendors, for example Compaq, Sun and HP, are experiencing strong sales growth it is strange that these are rated so poorly by the customers who actually buy and use these platforms. Customer comments about NT included "its fault diagnosis is terrible" (Cus 3) and "NT is trying to be scalable but it isn't proven yet - there are no terabyte data warehouses on it yet" (Cus 8). Further analysis in this paper will explain the reasons behind this.

The internal sales team also scored the four technology platforms. The results of this are shown in Table 7 . Table 7 shows that the ratings of the IBM sales team were significantly different to those from the customers. The IBM salesmen scored AS/400 first and System/390 second - whilst the customers scored these the other way around. Similarly, the IBM employees rated UNIX third and NT fourth - whilst the customers placed those in the reverse order also. The degree of difference was also less marked than that from the customers with $\mathrm{AS} / 400$ and $\mathrm{S} / 390$ being rated very similarly, and with much less difference between these and the scores of UNIX and NT. A comparison of the overall results for the evaluation of the server platforms by the customers and the IBM sales team is shown in table 8 .

In fact the IBM salesmen rated the platforms in the order which is best for IBM: AS/400 first (where IBM has $100 \%$ market share and therefore always wins), System/390 second (where IBM has over $90 \%$ market share and almost always wins), UNIX third (where IBM has approximately $20 \%$ share) and NT last (where IBM has $8 \%$ share and almost always loses). Whether this is the true perception, or whether it represents either wishful thinking or, perhaps, a strong belief in the Company's products (perhaps even a "not invented here" syndrome) is unclear from this analysis. What it does show is that IBM does not have a accurate understanding of how its products are rated by customers. This is significant - because in many cases IBM salesmen have to decide which platform to promote to a customer for a new application - this analysis would suggest that the salesmen might be promoting the wrong ones.

It is also feasible that there could be situations where IBM has supported AS/400, where a customer might have bought System $/ 390$, and IBM has then lost to an alternative UNIX or NT vendor in preference to AS/400. Certainly the IBM salesmen's low ranking of UNIX and NT may go a long way to explain IBM's inability to grow its UNIX and NT server businesses at anything like the rate of Sun or Compaq (who of course have only one product set and therefore face no such dilemma). 


\section{Individual Server Analysis}

Using the data from the software tool, it is possible to identify and map customers' attribute ratings for each individual server. The results for the $\mathrm{S} / 390$ are shown in figure 2.

For System/390, this identifies the following points:

- The System/390 has perceived strengths in manageability, application availability and hardware resilience.

- It has no perceived important weaknesses.

- Its strength in scalability is not very powerful because customers rate this attribute as being low in importance

- It has weaknesses in its setup time and cost of ownership, but these are not considered to be important attributes therefore the weaknesses have only a low impact.

\section{Competitive Positioning Against Other Platforms}

System/390's results when compared with those that follow for the other platforms, demonstrate the following comparisons:

- Against UNIX, System/390 has a clear advantage in its manageability, hardware resilience and application availability, and a less significant advantage in scalability. It has no disadvantages.

- Against NT, System/390 has a clear advantage in its manageability, hardware resilience and application availability, and less significant advantage in scalability. It less significant disadvantages in cost of ownership and setup time.

- Against AS/400, System/390 has a clear advantage in application availability, and a less significant advantage in scalability. It has no significant disadvantages, but has a minor disadvantage in setup time.

\section{Potential Improvements In Platform Position}

For System/390, this could be made in the following way:

1. Increasing the importance or perceived importance for customers of scalability so that this is seen as a relative strength of the System/390.

\section{DISCUSSION AND CONCLUSIONS}

It has been demonstrated that it is possible to use the MCDM technique to gather data which can be analysed in terms of: the importance of attributes; the overall positioning of different technical platforms against each of the attributes; and detailed analysis of individual platforms for particular vertical industries and solutions. Regarding the importance of individual attributes, it has been shown that from a customer perspective hardware resilience and application availability are considered to be the most important attributes, manageability and total cost of ownership are of middling importance, whilst scalability and setup time are of the least importance. Analysis of the IBM sales team showed that there are significant differences in their rating of these attributes. This needs to be addressed, as it is vital that the sales team understands the customers' key buying criteria.

On the overall positioning of the four servers against the product attributes some clear results emerged. Customers value the System/390 most highly, followed by AS/400, NT and finally UNIX. The rating given by the IBM sales team was again different. It is vital that the sales team proposes the server family that is most likely to be purchased by the customers. The detailed positioning of each technology platform against each attribute is shown in table 9. The data demonstrate the relative strengths and weaknesses of each technology platform.

It is also possible to use this process to find how an individual customer rates an attribute and a platform against the average for the market and how an industry group rates an attribute and a platform against the average for the market. For example, customers in the banking industry rate hardware resilience and S/390's ability to offer this more highly than manufacturers do. Similarly it is also possible to identify key differences between application areas. For example ERP customers scored hardware resilience with double the importance of the business intelligence customers.

This type of analysis should be used for positioning in marketing. It is clear that this analysis can identify valuable market information, and a more detailed study across a larger number of customers should now be designed and implemented by IBM. This should be used to build a bank of information, which, over time, will also allow the company to see how customer requirements change as products and solutions mature in the market. Because the data produced gives clear indications as to 
customer requirements, it should be made available to the sales-force in order that it can be used to IBM's advantage in individual sales campaigns.

The data should also be used to identify areas of weakness for further research and development. This type of data, which can be analysed by customer group, solutions area, and attribute provides extremely valuable information - not the least of which is the trade-offs which customers might be prepared to make in order to get the optimal server. IBM's sales team should be shown that System/390 is the customer's most highly rated server, and this should therefore be their first choice when considering which server to propose. High End Systems needs to address improving the internal IBM perception of System/390 as it is lower than that of $\mathrm{AS} / 400$ - whereas customers rate it much more highly. It is also probable that System/390 needs to have more solutions made available to operate on it.

The general contribution of the paper is that it proposes and tests a methodology that enables market researchers in a business market environment to measure and evaluate customer and supplier perceptions in a rigorous and practical manner. We have demonstrated the application of the Judgemental Analysis System (JAS) software on a major market, the European mainframe computer market, to analyze significant and important differences between the perception of the sales force team and the perception of the customer grouping. The market knowledge and insight gained from this study has had a major impact on the marketing strategy of the company in terms of its sales force training and promotional activities. The techniques are also being applied to help understand other market dynamics such as customer churn and platform switching.

The research method and results presented in this paper can be extended to take into account new developments in the computer and information systems market. For example, the increasing importance of the inter-dependency between the developments of new software applications and the hardware platform has been recognized by economists who have described these types of markets as two-sided platforms (e.g. see Eisenmann et al 2006 and Evans et al 2005) where the platform in this context is a broad service platform of inter-related technology products that collectively deliver value to the customer. The knowledge and insights gained from an increased understanding of the relative importance of different attributes can also be applied in related computing areas such as cloud computing and software as a service, which both represent huge growth opportunities for information technology companies, and are becoming of strategic importance to companies' IT plans.

\section{TABLES}

Table 1: Definition of Product Attributes

\begin{tabular}{|l|l|}
\hline Product Attributes & Definition \\
\hline Scalability & $\begin{array}{l}\text { The ability of the platform to grow to support larger number of users or greater } \\
\text { quantities of data without impacting performance. }\end{array}$ \\
\hline Hardware Resilience & $\begin{array}{l}\text { The ability of the platform to withstand unplanned hardware outages without } \\
\text { impacting users. }\end{array}$ \\
\hline $\begin{array}{l}\text { Application } \\
\text { Availability }\end{array}$ & $\begin{array}{l}\text { The uptime of the application - factoring in database re-orgs, operating system } \\
\text { upgrades, and other planned outages }\end{array}$ \\
\hline Manageability & $\begin{array}{l}\text { How easy it is to manage and operate the product, factoring in for example whether } \\
\text { the customer has existing skills. }\end{array}$ \\
\hline $\begin{array}{l}\text { Total Cost of } \\
\text { Ownership }\end{array}$ & $\begin{array}{l}\text { All costs over the life of the product, including up front initial purchase capital costs } \\
\text { and operating revenue costs. }\end{array}$ \\
\hline Setup Time & $\begin{array}{l}\text { The time within which the product and its application can be set up and operating to } \\
\text { deliver a business service }\end{array}$ \\
\hline
\end{tabular}

Table 2: Industry Segment and Solution Area Matrix

\begin{tabular}{|l|l|l|l|l|l|}
\hline & Business Intelligence & ERP & e-Business & $\begin{array}{l}\text { Server } \\
\text { Consolidation }\end{array}$ & $\begin{array}{l}\text { Core Industry } \\
\text { Applications }\end{array}$ \\
\hline Banking, Finance \& Securities & 4 & 1 & & & 1 \\
\hline Insurance & & & 1 & & \\
\hline Small \& Medium Business & & 3 & & & \\
\hline Distribution & & 3 & & 2 & \\
\hline Manufacturing & & 3 & & & \\
\hline
\end{tabular}


Table 3: Product Attribute Scores by Customers

\begin{tabular}{|c|c|c|c|c|c|c|}
\hline & Product A & utes & & & & \\
\hline & Scalability & $\begin{array}{l}\text { Hardware } \\
\text { resilience }\end{array}$ & $\begin{array}{l}\text { Application } \\
\text { availability }\end{array}$ & Manageability & $\begin{array}{l}\text { Total Cost of } \\
\text { Ownership }\end{array}$ & Setup Time \\
\hline Cus 1 & 25.8 & 9.9 & 22.9 & 21.2 & 10.1 & 10.1 \\
\hline Cus 2 & 6.8 & 19.5 & 17.3 & 29.0 & 20.7 & 6.8 \\
\hline Cus 3 & 8.1 & 35.6 & 27.1 & 8.5 & 19.4 & 1.2 \\
\hline Cus 4 & 13.2 & 30.8 & 30.8 & 8.6 & 6.2 & 10.4 \\
\hline Cus 5 & 12.0 & 48.2 & 24.1 & 12.0 & 1.2 & 2.4 \\
\hline Cus 6 & 5.9 & 25.4 & 24.6 & 10.5 & 30.4 & 3.1 \\
\hline Cus 7 & 9.7 & 48.2 & 12.3 & 3.8 & 24.8 & 1.4 \\
\hline Cus 8 & 12.6 & 4.2 & 7.3 & 38.8 & 8.5 & 28.6 \\
\hline Cus 9 & 2.7 & 27.5 & 27.5 & 27.5 & 0.3 & 14.6 \\
\hline Cus 10 & 8.5 & 16.5 & 18.1 & 24.8 & 24.4 & 7.7 \\
\hline Cus 11 & 21.2 & 18.3 & 13.0 & 18.3 & 20.0 & 9.1 \\
\hline Cus 12 & 4.7 & 25.7 & 30.3 & 17.5 & 12.3 & 9.5 \\
\hline Cus 13 & 15.7 & 25.3 & 25.1 & 17.1 & 10.6 & 6.3 \\
\hline Cus 14 & 19.2 & 15.4 & 17.8 & 13.8 & 21.4 & 12.3 \\
\hline Cus 15 & 17.8 & 22.0 & 15.6 & 13.9 & 18.4 & 12.2 \\
\hline Average & 12.3 & 24.8 & 20.9 & 17.7 & 15.2 & 9.0 \\
\hline Rank & 5 & 1 & 2 & 3 & 4 & 6 \\
\hline
\end{tabular}

Table 4: The Supplier Evaluation of the Product Attributes

\begin{tabular}{|lllllll|}
\hline & $\begin{array}{l}\text { Attributes } \\
\text { Scalability }\end{array}$ & $\begin{array}{l}\text { Hardware } \\
\text { resilience }\end{array}$ & $\begin{array}{l}\text { Application } \\
\text { availability }\end{array}$ & Manageability & $\begin{array}{l}\text { Total Cost of } \\
\text { Ownership }\end{array}$ & Setup Time \\
Sales1 & 13.6 & 16.7 & 23.3 & 10.0 & 22.4 & 13.9 \\
Sales2 & 16.5 & 16.6 & 16.6 & 16.7 & 17.0 & 16.7 \\
Sales3 & 16.5 & 14.0 & 16.5 & 16.5 & 18.2 & 18.2 \\
Sales4 & 11.2 & 6.8 & 15.8 & 15.9 & 28.3 & 22.0 \\
Sales5 & 12.4 & 13.3 & 24.9 & 23.2 & 18.5 & 7.7 \\
Sales6 & 20.3 & 9.9 & 19.0 & 25.0 & 20.7 & 5.0 \\
Rank & $\mathbf{4}$ & $\mathbf{6}$ & $\mathbf{2}$ & $\mathbf{3}$ & $\mathbf{1}$ & $\mathbf{5}$ \\
\hline
\end{tabular}

Table 5: A Comparison of Supplier and Customer Scores

\begin{tabular}{|lllllll|}
\hline & $\begin{array}{l}\text { Attributes } \\
\text { Scalability }\end{array}$ & $\begin{array}{l}\text { Hardware } \\
\text { resilience }\end{array}$ & $\begin{array}{l}\text { Application } \\
\text { availability }\end{array}$ & Manageability & $\begin{array}{l}\text { Total Cost of } \\
\text { Ownership }\end{array}$ & Setup Time \\
Customer & 12.3 & 24.8 & 20.9 & 17.7 & 15.2 & 9.0 \\
$\begin{array}{l}\text { Average } \\
\text { Rank }\end{array}$ & 5 & 1 & 2 & 3 & 4 & 6 \\
Internal & 15.1 & 12.9 & 19.4 & 17.9 & 20.9 & 13.9 \\
$\begin{array}{l}\text { Average } \\
\text { Rank }\end{array}$ & 4 & 6 & 2 & 3 & 1 & 5 \\
\hline
\end{tabular}


Table 6: Platform Positioning Analysis - Customers

\begin{tabular}{|lllllllll|}
\hline Platforms & UNIX & & NT & & AS/400 & \multicolumn{2}{c|}{ System/390 } \\
& Average & Rank & Average & Rank & Average & Rank & Average & Rank \\
Cus 1 & 29.7 & 1 & 19.8 & 4 & 20.9 & 3 & 29.5 & 2 \\
Cus 2 & 21.5 & 2 & 9.8 & 4 & 21.5 & 2 & 47.3 & 1 \\
Cus 3 & 16.9 & 4 & 22.1 & 2 & 39.9 & 1 & 21.0 & 3 \\
Cus 4 & 15.8 & 2 & 6.6 & 4 & 14.6 & 3 & 63.0 & 1 \\
Cus 5 & 10.8 & 3 & 9.3 & 4 & 31.9 & 2 & 48.0 & 1 \\
Cus 6 & 10.4 & 4 & 30.7 & 2 & 32.3 & 1 & 26.6 & 3 \\
Cus 7 & 17.8 & 4 & 24.3 & 3 & 31.2 & 1 & 26.7 & 2 \\
Cus 8 & 20.3 & 2 & 11.8 & 3 & 7.9 & 4 & 60.1 & 1 \\
Cus 9 & 7.5 & 4 & 18.1 & 3 & 39.6 & 1 & 34.8 & 2 \\
Cus 10 & 19.4 & 3 & 13.6 & 4 & 22.8 & 2 & 44.2 & 1 \\
Cus 11 & 20.0 & 3 & 15.7 & 4 & 29.7 & 2 & 34.6 & 1 \\
Cus 12 & 7.6 & 3 & 26.4 & 2 & 7.6 & 3 & 58.5 & 1 \\
Cus 13 & 12.1 & 3 & 12.2 & 2 & 12.1 & 3 & 63.6 & 1 \\
Cus 14 & 23.8 & 3 & 23.1 & 4 & 25.7 & 2 & 27.4 & 1 \\
Cus 15 & 24.1 & 3 & 22.2 & 4 & 25.8 & 2 & 27.8 & 1 \\
Average & 17.2 & 4 & 17.7 & 3 & 24.2 & 2 & 40.9 & 1 \\
\hline
\end{tabular}

Table 7: Internal Server Scores

\begin{tabular}{|c|c|c|c|c|c|c|c|c|}
\hline & Platforms & & & & & & & \\
\hline & UNIX & & NT & & $\mathrm{AS} / 400$ & & System $/ 3$ & \\
\hline & Average & Rank & Average & Rank & Average & Rank & Average & Rank \\
\hline Sales 1 & 20.5 & 3 & 14.2 & 4 & 32.4 & 2 & 32.9 & 1 \\
\hline Sales2 & 24.7 & 4 & 24.8 & 3 & 25.0 & 2 & 25.5 & 1 \\
\hline Sales3 & 22.2 & 3 & 22.8 & 2 & 22.2 & 3 & 32.9 & 1 \\
\hline Sales4 & 15.6 & 4 & 18.6 & 3 & 37.1 & 1 & 28.7 & 2 \\
\hline Sales5 & 20.9 & 3 & 12.5 & 4 & 43.5 & 1 & 23.1 & 2 \\
\hline Sales6 & 26.3 & 3 & 4.6 & 4 & 28.0 & 2 & 41.1 & 1 \\
\hline Average & 21.7 & 3 & 16.3 & 4 & 31.4 & 1 & 30.7 & 2 \\
\hline
\end{tabular}

Table 8: A Comparison of Customer and IBM Server Scores

\begin{tabular}{|c|c|c|c|c|c|c|c|c|}
\hline \multirow{4}{*}{$\begin{array}{l}\text { Customer } \\
\text { IBM }\end{array}$} & $\begin{array}{l}\text { Platforms } \\
\text { UNIX }\end{array}$ & \multicolumn{6}{|c|}{ Platforms } & \\
\hline & Average & Rank & Average & Rank & Average & Rank & Average & Rank \\
\hline & 17.2 & 4 & 17.7 & 3 & 24.2 & 2 & 40.9 & 1 \\
\hline & 21.7 & 3 & 16.3 & 4 & 31.4 & 1 & 30.7 & 2 \\
\hline
\end{tabular}


Table 9: Comparative Platform Strengths and Weaknesses

\begin{tabular}{|l|l|l|l|l|}
\hline & Platform Strengths & Platform Weaknesses & Potential & Low Impact \\
\hline UNIX & & $\begin{array}{l}\text { Application Availability } \\
\text { Hardware Resilience } \\
\text { Manageability }\end{array}$ & $\begin{array}{l}\text { Setup Time Scalability } \\
\text { Cost of Ownership }\end{array}$ \\
\hline Windows NT & $\begin{array}{l}\text { Application Availability } \\
\text { Hardware Resilience } \\
\text { Manageability }\end{array}$ & $\begin{array}{l}\text { Setup Time } \\
\text { Cost of Ownership }\end{array}$ & Scalability \\
\hline AS/400 & $\begin{array}{l}\text { Hardware Resilience } \\
\text { Manageability }\end{array}$ & Application Availability & $\begin{array}{l}\text { Setup Time } \\
\text { Cost of Ownership }\end{array}$ & Scalability \\
\hline System/390 & $\begin{array}{l}\text { Hardware Resilience } \\
\text { Application Availability } \\
\text { Manageability }\end{array}$ & Scalability & $\begin{array}{l}\text { Setup Time } \\
\text { Cost of Ownership }\end{array}$ \\
\hline
\end{tabular}

\section{FIGURES}

Figure 1: Competitor Market Evaluation Using Judgemental Analysis

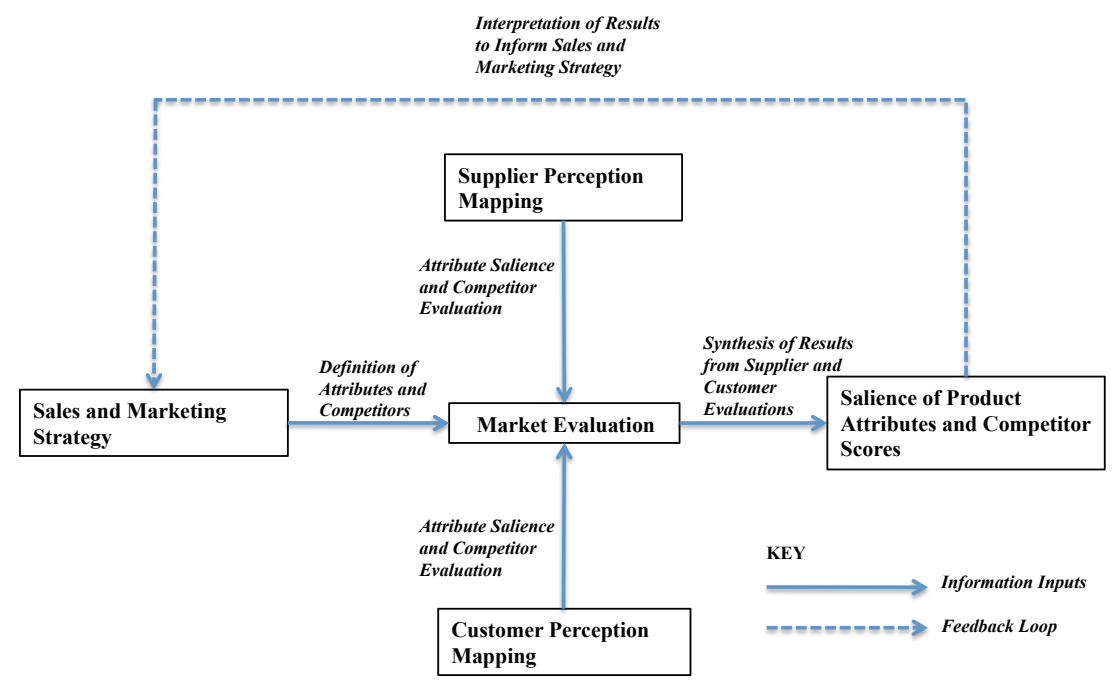

Figure 2: S/390 Platform Rating/Attribute Salience Analysis Matrix

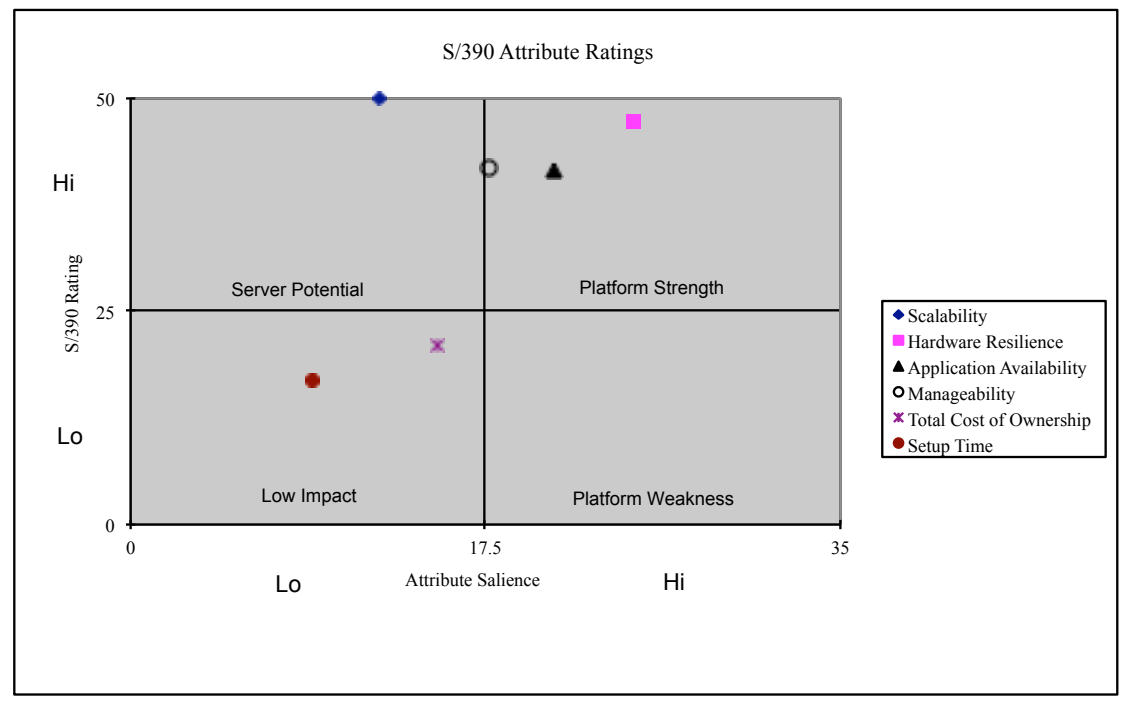




\section{REFERENCES}

Anchordoguy, M. (1988). "Mastering the Market: Japanese government targeting of the computer industry." International Organization 42(3): 519-543.

Anchordoguy, M. (1989). Computers Inc., Japan's Challenge to IBM. Massachusetts: Harvard University Press.

Bresnahan, T.F. and S. Greenstein (1999). "Technological Competition and the Structure of the Computer Industry." The Journal of Industrial Economics 47 (1): 1-40.

Christensen, C.M. (1997). The Innovator's Dilemma, When New Technologies Cause Great Firms to Fail. Massachusetts: Harvard Business School Press: 108-110.

Crissey, J. (1998). EMEA High End Systems Marketing Plan Overview. IBM internal presentation.

Eisenhardt, K.M. (1989). “Building Theories from Case Study Research.” Academy of Management Review 14 (4): $532-550$.

Eisenmann, T., G. Parker and M. W. Van Alstyne (2006). "Strategies for Two-Sided Markets." Harvard Business Review 84 (10): 92-101.

Evans, D.S., A. Hagiu and R. Schmalensee (2005). "A Survey of the Economic Role of Software Platforms in Computerbased Industries.” CESifo Economic Studies 51 (2-3): 189-224.

Hammond, D. (March 1998). IBM EMEA High End Server Business. Personal interview with the author.

Harmer, B. (1997). S/390 EMEA Competitor Analysis. IBM EMEA Market Intelligence internal IBM document.

Holland, C P. and B. Light. "A Critical Success Factors Model for Enterprise Resource Planning (ERP) Implementation." IEEE Software 16 (3): 30-35.

IBM (1998). Large Customer IT Panel Survey. IBM internal presentation.

IBM (1999). Industry Trends in EMEA - An assessment of business opportunities and the competitive environment, a focus on large companies. IBM EMEA Market Intelligence internal report.

Islei, G. and A.G. Lockett (1988). "Judgemental modelling based on geometric least square." European Journal of Operational Research 36 (1): 27-35.

Islei, G. and A.G. Lockett. JAS for Windows Version 1.0 PC Software. Manchester Business School.

Kirkpatrick, D. (1998). “The E-Ware War - Competition Comes to Enterprise Software.” Fortune 138 (11).

Lockett, G. and P. Naude (1991). "Winning a Large Order: A Case Study Using Judgemental Modelling." Industrial Marketing Management 20: 169-175.

Malerba, F., R. Nelson, L. Orsenigo and S. Winter (1999). "History-friendly Models of Industry Evolution: The Computer Industry." Industrial and Corporate Change 8 (1): 3-40.

McEachern, T. and R. O'Keefe (1998). Re-Wiring Business: Uniting Management and the Web. New York: John Wiley \& Sons.

Mohr, J.J., S. Sengupta, S. Slater (2010). Marketing of High-Technology Products and Innovations. New Jersey: Pearson Education $3^{\text {rd }}$ edition. 
Naude, P. and Lockett, G. (1993). "Market Analysis via Judgemental Modelling - An Application in the UK Chemical Industry.” European Journal of Marketing 27 (3): 5-22.

Naudé, P., A.G. Lockett, G.Islei and P. Drinkwater (2000). “An exploration into the influence of psychological profiles upon group decision making." Journal of the Operational Research Society 51 (2): 168-175.

Rafiq, M. (1998). OMSYS Measurement System. IBM internal paper.

Robinson, P.J., C.W. Faris and Y. Wind. Industrial Buying and Creative Marketing. Boston: Allyn \& Bacon.

Saaty, T.L. (1980). The Analytic Hierarchy Process. New York: McGraw Hill.

Waldspurger, C.A. (2002). "Memory Resource Management in VMware ESX." Proceedings Fifth Symposium on Operating Systems Design and Implementation, Massachusetts: OSDI '02 Dec.

Watson, H.J. and B.H. Wixom (2007). “The Current State of Business Intelligence.” Computer (September): $96-99$.

Wind, Y. and T.L. Saaty (1980). "Marketing Applications of the Analytic Hierarchy Process." Marketing Science 26 (7): 641-658.

Wind Y. (1982). Product Policy: Concepts, Methods and Strategy. Reading, Massachusetts: Addison-Wesley Marketing Series. 